\title{
Cognitive Dysfunction Among Adults With Type 2 Diabetes Mellitus in Karnataka, India
}

\author{
Devesh Bhaskar Yerrapragada, MBBS, Chythra R. Rao, MD, Kavinya Karunakaran, MBBS, \\ Henry Seow Ern Lee, MBBS
}

Department of Community Medicine, Kasturba Medical College, Manipal Academy of Higher Education, Manipal, Karnataka, India

\begin{abstract}
Background: Type 2 diabetes mellitus is a chronic metabolic disease characterized by hyperglycemia that affects various body systems. Elevated blood glucose levels cause brain malfunction, sorbitol-induced blood vessel damage, and degeneration of the nerves that can lead to dementia or cognitive impairment. Cognitive impairment can result in nonadherence of patients to diabetes treatment, such as diet, medication, and exercise.

Methods: We used a cross-sectional design to individually interview 194 patients with type 2 diabetes in a rural field practice area in India. A questionnaire was used to collect sociodemographic and diabetes disease characteristics; anthropometric measurements were also collected. Cognitive dysfunction was assessed with the Kannada version (local language) of the Montreal Cognitive Assessment (MoCA) tool. Blood pressure was measured for all subjects using a standardized sphygmomanometer on the right arm with the patient in a sitting position.

Results: Among the 194 diabetic subjects interviewed, 98 (50.5\%) were cognitively impaired. More than half of the subjects (56.2\%) were $\geq 65$ years, and female participants (53.6\%) outnumbered males (46.4\%). The majority of patients (62.4\%) had had diabetes for $<10$ years. The sociodemographic characteristics age, sex, education, occupation, and socioeconomic status and the anthropometric measurement of waist-to-hip ratio were significantly associated $(P<0.05)$ with cognitive impairment. Disease characteristics, religion, and blood pressure showed no significant association with cognitive impairment.

Conclusion: One in two individuals with type 2 diabetes mellitus in our study population had mild cognitive impairment. Older individuals in the low socioeconomic strata and with low levels of education were identified to be at high risk of cognitive impairment. Hence, screening and appropriate care need to be provided.
\end{abstract}

Keywords: Cognitive dysfunction, cross-sectional study, diabetes mellitus-type 2, mental status and dementia tests

Address correspondence to Chythra R. Rao, MD, Department of Community Medicine, Kasturba Medical College, Manipal Academy of Higher Education, Manipal 576104, Karnataka, India. Tel: +91-820-292-2324. Email: chythra.raj@manipal.edu

\section{INTRODUCTION}

Diabetes mellitus is a chronic metabolic disease characterized by hyperglycemia that affects various body systems. For this progressive, incurable condition, the best scenario after diagnosis is good metabolic control and risk factor management to forestall vascular and neuropathic complications. ${ }^{1}$ People with diabetes often develop diverse microvascular, macrovascular, and neuropathic complications that erode quality of life, making diabetes a major concern for much of the developed and developing world. ${ }^{2,3}$ The increasing population and increasing sedentary lifestyle worldwide have led to a rise in diabetes, with a $72 \%$ increase in the disease projected by 2030.4

The impaired insulin metabolism in patients with diabetes results in widespread morbidities involving the retinal, renal, cardiovascular, and peripheral nervous systems ${ }^{5}$ and also affects cognition. ${ }^{6}$ Elevated blood glucose levels not only cause brain malfunction but also promote the syn- thesis of sorbitol, which damages blood vessels and causes degeneration of the nerves. ${ }^{7}$ Oxidative stress, microvascular vasculopathy, inflammation, and dyslipidemia are other key mediators ${ }^{8}$ resulting in neuropathology that can lead to dementia or cognitive impairment.

Patients are said to be cognitively impaired when they have difficulty remembering, learning new things, concentrating, or making decisions that affect everyday life. ${ }^{9}$ Cognitive impairment, especially for people with chronic diseases, is likely to be an obstacle to providing appropriate medical treatment, as patients' understanding of the need for treatment, regular follow-up, and self-care can be limited by the cognitive dysfunction. ${ }^{10}$ Cognitive functions that enable complex behaviors are particularly important for patients with diabetes. Cognitive impairment might result in nonadherence with diet, medication, and exercise. ${ }^{11}$ Older patients with diabetes and concomitant cognitive dysfunction may be unable to follow complicated regimens 
(eg, multiple daily insulin injections with or without a sliding scale, multiple oral medications, or a complex dietary regimen). ${ }^{12}$ These patients may be at increased risk of treatment complications (eg, omission of meals leading to hypoglycemia or incorrect dose or timing of insulin injections and/or oral medications). ${ }^{13}$ Cognitive impairment also increases the risk of major cardiovascular events and all-cause mortality. ${ }^{14}$

Studies about the relationship between cognitive impairment and diabetes mellitus are inconclusive because of inconsistent reports. The inconsistency in findings may be attributable to differences in study design, study subjects, duration or severity of diabetes, and the tools used for assessment of cognitive impairment. ${ }^{15}$ One such tool, the Montreal Cognitive Assessment (MoCA), was developed to screen for mild cognitive impairment, ${ }^{16}$ but few studies ${ }^{17,18}$ have reported using the MoCA in community settings. A pilot study from Canada reported the MoCA to be a better screening tool than the Standardized Mini-Mental State Examination for mild cognitive impairment in the diabetic population. ${ }^{19}$

Although diabetes is considered a risk factor for cognitive impairment, the cognitive function of patients with type 2 diabetes is not usually evaluated in routine clinical care. The purpose of this study was to screen for mild cognitive impairment among patients with diabetes in the state of Karnataka in southwestern India.

\section{METHODS}

We used a cross-sectional design to interview 194 patients with type 2 diabetes mellitus who resided in the field practice area of the Department of Community Medicine, attached to Kasturba Medical College in the coastal town of Manipal in southwestern India. Institutional ethical committee clearance was obtained before the initiation of the study (IEC 124/2016). The study conformed to the principles of the Declaration of Helsinki. Written informed consent was obtained from all the study subjects.

Study participants were identified with the help of auxiliary nurse midwives in the field practice area. Patients of both sexes who were $\geq 30$ years of age, diagnosed with type 2 diabetes mellitus for at least 2 years, and willing to participate were eligible for inclusion. Patients with type 2 diabetes mellitus who had severe comorbidities such as stroke or documented mental illness, those with speech and hearing disabilities that would interfere with providing answers to the questionnaire, and pregnant females were excluded. Assuming the prevalence of cognitive dysfunction among adults with type 2 diabetic mellitus to be $25 \%$ and accounting for an alpha error of $5 \%$ at $25 \%$ relative precision and a $5 \%$ nonresponse rate, the sample size was calculated to be 194 by application of the formula $4 \mathrm{pq} / \mathrm{d}^{2}$ used for sample size estimation of cross-sectional studies.

Sociodemographic characteristics, details about patients' disease and treatment, and anthropometric measurements were collected during personal interviews according to a predesigned questionnaire. The faculty of the Department of Community Medicine designed the questionnaire and use it routinely for community-based studies. The authors conducted the interviews.

Socioeconomic status was assessed using a modified Udai Pareekh scale ${ }^{20}$ that includes the following domains: type of house, ownership, landholding, vehicles, household belongings, livestock, social participation, occupation of the eldest earning member of the household, and family members working abroad. The scores for the domains are summed. A score $<40$ is considered low socioeconomic status, 40 to 70 is considered middle, and $>70$ is considered high socioeconomic status.

Cognitive dysfunction was assessed through the administration of the Kannada version (local language) of the MoCA. Permission was obtained to use the MoCA and the translated version. The MoCA assesses 7 cognitive domains: visuospatial/executive (5 points), naming (3 points), memory (5 points for delayed recall), attention (6 points), language ( 3 points), abstraction ( 2 points), and orientation (6 points); the upper score limit is 30 points. One point is added if the subject has $\leq 12$ years of education. The cutoff value is 26 . A score $\geq 26$ is considered normal. ${ }^{16}$

In addition, blood pressure was measured for all subjects using a standardized mercury sphygmomanometer on the right arm with the patient in a seated position. If the patient's blood pressure was $\geq 140 / 90 \mathrm{~mm} \mathrm{Hg}$, a repeat blood pressure reading was taken after 5 minutes. The average of the readings was recorded as the blood pressure of the participant. Blood pressure was classified according to Joint National Committee VII criteria. ${ }^{21}$

\section{Anthropometric Variables}

All the anthropometric measurements were performed according to World Health Organization (WHO) guidelines, and quality control was maintained during collection of data. ${ }^{18}$ Patients wore light clothing when the following measurements were taken: weight, height, waist circumference, and hip circumference.

Waist-to-hip ratio was calculated by dividing waist circumference in $\mathrm{cm}$ by hip circumference in $\mathrm{cm}$. Body mass index (BMI) was calculated by dividing weight in $\mathrm{kg}$ by height in square meters. Overweight and obesity were defined as follows:

- BMI (WHO classification): $\geq 25.0 \mathrm{~kg} / \mathrm{m}^{2}$ (overweight) and $\geq 30.0 \mathrm{~kg} / \mathrm{m}^{2}$ (obese) ${ }^{22}$

- BMI (Southeast Asian classification): $\geq 23.0 \mathrm{~kg} / \mathrm{m}^{2}$ (overweight) and $\geq 25.0 \mathrm{~kg} / \mathrm{m}^{2}$ (obese) (o $^{23}$

- Waist-to-hip ratio $\geq 0.90$ for males and $\geq 0.85$ for females (truncal obesity) ${ }^{24}$

- Waist circumference $>90 \mathrm{~cm}$ in males and $>80 \mathrm{~cm}$ in females (central/abdominal obesity) ${ }^{24}$

\section{Data Analysis}

Data were entered and analyzed using the Statistical Package for Social Sciences (IBM) v.15. The results are summarized as percentages and proportions. Chi-square test was used for univariate analysis. The association between categorical variables and the presence of cognitive dysfunction was assessed by univariate analysis. A $P$ value $<0.05$ was considered significant.

\section{RESULTS}

Among the 194 patients who were interviewed, 98 (50.5\%) were cognitively impaired (score $\leq 25$ on the MoCA). The highest mean score was in the domain of orientation (5.53), 
Table 1. Association Between Cognitive Dysfunction and Sociodemographic Characteristics of the Study Participants

\begin{tabular}{|c|c|c|c|c|}
\hline Variable & $\begin{array}{l}\text { All Patients } \\
\begin{array}{c}(n=194) \\
n(\%)\end{array}\end{array}$ & $\begin{array}{c}\text { Cognitive } \\
\text { Dysfunction } \\
\text { Present }(n=98), \\
n(\%)\end{array}$ & $\begin{array}{c}\text { Cognitive } \\
\text { Dysfunction } \\
\text { Absent }(n=96) \text {, } \\
n(\%)\end{array}$ & $P$ Value \\
\hline \multicolumn{5}{|l|}{ Age, years } \\
\hline$<45$ & $10(5.2)$ & $5(5.1)$ & $5(5.2)$ & \multirow[t]{4}{*}{0.009} \\
\hline $45-54$ & $22(11.3)$ & $4(4.1)$ & 18 (18.8) & \\
\hline $55-64$ & $53(27.3)$ & $26(26.5)$ & $27(28.1)$ & \\
\hline$\geq 65$ & 109 (56.2) & $63(64.3)$ & 46 (47.9) & \\
\hline \multicolumn{5}{|l|}{ Sex } \\
\hline Female & 104 (53.6) & $62(63.3)$ & $42(43.8)$ & \multirow[t]{2}{*}{0.006} \\
\hline Male & $90(46.4)$ & $36(36.7)$ & $54(56.2)$ & \\
\hline \multicolumn{5}{|l|}{ Religion } \\
\hline Hindu & $126(64.9)$ & $62(63.3)$ & $64(66.7)$ & \multirow[t]{3}{*}{0.656} \\
\hline Christian & $31(16.0)$ & 18 (18.4) & $13(13.5)$ & \\
\hline Muslim & $37(19.1)$ & $18(18.4)$ & 19 (19.8) & \\
\hline \multicolumn{5}{|l|}{ Education $^{a}$} \\
\hline Illiterate & $16(8.2)$ & $15(15.3)$ & $1(1.0)$ & \multirow[t]{4}{*}{$<0.001$} \\
\hline Grade 1-4 & 34 (17.5) & $21(21.4)$ & $13(13.5)$ & \\
\hline Grade 5-12 & $112(57.7)$ & $55(56.1)$ & $57(59.4)$ & \\
\hline Graduate & $32(16.4)$ & $7(7.1)$ & $25(26.0)$ & \\
\hline \multicolumn{5}{|l|}{ Occupation } \\
\hline Homemaker & $95(49.0)$ & $59(60.2)$ & 36 (37.5) & \multirow[t]{3}{*}{0.003} \\
\hline Retired & $66(34.0)$ & $29(29.6)$ & 37 (38.5) & \\
\hline Skilled & $33(17.0)$ & $10(10.2)$ & $23(24.0)$ & \\
\hline \multicolumn{5}{|c|}{ Socioeconomic status } \\
\hline Low & $34(17.5)$ & $25(25.5)$ & $9(9.4)$ & \multirow[t]{3}{*}{0.008} \\
\hline Middle & 159 (82.0) & $73(74.5)$ & $86(89.6)$ & \\
\hline High & $1(0.5)$ & $0(0)$ & $1(1.0)$ & \\
\hline
\end{tabular}

while the lowest mean score was in the domain of abstraction (1.78).

Among the study participants, $162(83.5 \%)$ were $\geq 55$ years, females (53.6\%) outnumbered males $(46.4 \%), 8.2 \%$ were illiterate, $49.0 \%$ were homemakers, and $82.0 \%$ were assessed as middle class (Table 1). Age, sex, education, occupation, and socioeconomic status were associated with cognitive dysfunction.

Among those cognitively impaired, 89 (90.8\%) were $\geq 55$ years. A higher proportion of females had cognitive dysfunction compared to males, 62 (63.3\%) vs 36 (36.7\%), respectively.

Approximately $70 \%$ of participants were diagnosed with diabetes after age 50 years (Table 2), so a small percentage $(15.5 \%)$ had had the disease for $\geq 20$ years. More than $90 \%$ of the study subjects were on regular treatment, with the majority $(82.0 \%)$ exclusively on oral antidiabetic medications. Most patients had regular blood sugar monitoring, $46.9 \%$ at a frequency of $\leq 1$ month and $41.8 \%$ at 2 to 3 months. None of the disease characteristics or treatment variables was associated with cognitive dysfunction.

The number of patients classified as obese differed according to the definition applied. Based on waist circumference, 158 (81.4\%) study participants were obese. However, waist-to-hip ratio identified 174 (89.7\%) obese patients. In a comparison of the Southeast Asian BMI classification vs the WHO BMI classification, more patients were obese according to the Southeast Asian criteria: $52.1 \%$ with a $\mathrm{BMI} \geq 25.0 \mathrm{~kg} / \mathrm{m}^{2}$ vs $14.9 \%$ with a $\mathrm{BMl} \geq 30.0 \mathrm{~kg} / \mathrm{m}^{2}$, respectively.

Among the patients with cognitive dysfunction, $81.6 \%$ had central/abdominal obesity based on waist circumference, and $84.7 \%$ had truncal obesity based on waist-to-hip ratio. 
Table 2. Association Between Cognitive Dysfunction and Disease Characteristics/Treatment of the Study Participants

\begin{tabular}{|c|c|c|c|c|}
\hline Variable & $\begin{array}{l}\text { All Patients } \\
\begin{array}{c}(n=194) \\
n(\%)\end{array}\end{array}$ & $\begin{array}{c}\text { Cognitive Dysfunction } \\
\text { Present } \\
(\mathrm{n}=98) \\
\mathrm{n}(\%)\end{array}$ & $\begin{array}{c}\text { Cognitive Dysfunction } \\
\text { Absent } \\
(\mathrm{n}=96) \\
\mathrm{n}(\%)\end{array}$ & $P$ Value \\
\hline Age at diagnosis, years & & & & 0.443 \\
\hline$<40$ & $22(11.3)$ & $9(9.2)$ & $13(13.5)$ & \\
\hline $40-49$ & $37(19.1)$ & $16(16.3)$ & $21(21.9)$ & \\
\hline $50-59$ & $70(36.1)$ & $36(36.7)$ & $34(35.4)$ & \\
\hline$\geq 60$ & $65(33.5)$ & $37(37.8)$ & $28(29.2)$ & \\
\hline Duration of disease, years & & & & 0.381 \\
\hline$<10$ & $121(62.4)$ & $56(57.1)$ & $65(67.7)$ & \\
\hline $10-19$ & $43(22.2)$ & $23(23.5)$ & $20(20.8)$ & \\
\hline 20-29 & $20(10.3)$ & $13(13.3)$ & $7(7.3)$ & \\
\hline$\geq 30$ & $10(5.2)$ & $6(6.1)$ & $4(4.2)$ & \\
\hline Duration of treatment, years & & & & 0.457 \\
\hline$<10$ & $122(62.9)$ & $55(58.2)$ & $65(67.7)$ & \\
\hline $10-19$ & $43(22.2)$ & $23(23.5)$ & $20(20.8)$ & \\
\hline $20-29$ & $20(10.3)$ & $13(13.3)$ & $7(7.3)$ & \\
\hline$\geq 30$ & $9(4.6)$ & $5(5.1)$ & $4(4.2)$ & \\
\hline Type of treatment & & & & 0.607 \\
\hline Antidiabetic medications & $159(82.0)$ & $81(82.7)$ & $78(81.3)$ & \\
\hline Insulin & $9(4.6)$ & $5(5.1)$ & $4(4.2)$ & \\
\hline Both insulin and oral medicines & $13(6.7)$ & $8(8.2)$ & $5(5.2)$ & \\
\hline Ayurveda & $3(1.5)$ & $1(1.0)$ & $2(2.1)$ & \\
\hline No treatment & $6(3.1)$ & $1(1.0)$ & $5(5.2)$ & \\
\hline Lifestyle modification & $4(2.1)$ & $2(2.0)$ & $2(2.1)$ & \\
\hline Regular treatment & & & & 0.396 \\
\hline Yes & $179(92.3)$ & $92(93.9)$ & $87(90.6)$ & \\
\hline No & $15(7.7)$ & $6(6.1)$ & $9(9.4)$ & \\
\hline Place of treatment & & & & 0.761 \\
\hline Rural health center & $12(6.2)$ & $5(5.1)$ & $7(7.3)$ & \\
\hline Government hospital & $38(19.6)$ & $17(17.3)$ & $21(21.9)$ & \\
\hline Private hospital & $76(39.2)$ & $42(42.9)$ & $34(35.4)$ & \\
\hline Secondary care hospital & $33(17.0)$ & $16(16.3)$ & $17(17.7)$ & \\
\hline Tertiary care hospital & $35(18.0)$ & $18(18.4)$ & $17(17.7)$ & \\
\hline Frequency of blood sugar monitoring & & & & 0.569 \\
\hline Never & $3(1.5)$ & $0(0)$ & $3(3.1)$ & \\
\hline$<1$ month & $91(46.9)$ & $50(51.0)$ & $41(42.7)$ & \\
\hline $2-3$ months & $81(41.8)$ & 39 (39.8) & $42(43.8)$ & \\
\hline$>6$ months & $19(9.8)$ & $9(9.2)$ & $10(10.4)$ & \\
\hline
\end{tabular}

However, $54.1 \%$ (53 of 98 patients with cognitive dysfunction) had a BMl $<25.0 \mathrm{~kg} / \mathrm{m}^{2}$.

High blood pressure was detected among 109 (56.2\%) of the study participants. No association was found between blood pressure and cognitive dysfunction: $58.2 \%$ of patients with cognitive dysfunction had elevated blood pressure compared to $54.2 \%$ of patients without cognitive impairment.

\section{DISCUSSION}

Type 2 diabetes mellitus is associated with accelerated cognitive decline, ${ }^{25}$ and poor glycemic control is implicated 
Table 3. Association Between Cognitive Dysfunction and Anthropometric Measurements/Blood Pressure of the Study Participants

\begin{tabular}{|c|c|c|c|c|}
\hline Variable & $\begin{array}{l}\text { All Patients } \\
\begin{array}{c}(n=194), \\
n(\%)\end{array}\end{array}$ & $\begin{array}{l}\text { Cognitive } \\
\text { Dysfunction Present } \\
\begin{array}{c}(\mathrm{n}=98), \\
\mathrm{n}(\%)\end{array}\end{array}$ & $\begin{array}{c}\text { Cognitive } \\
\text { Dysfunction Absent } \\
\begin{array}{c}(\mathrm{n}=96) \\
\mathrm{n}(\%)\end{array}\end{array}$ & $P$ Value \\
\hline Waist circumference, $\mathrm{cm}$ & & & & 0.945 \\
\hline Normal & $36(18.6)$ & $18(18.4)$ & $18(18.8)$ & \\
\hline Obese ( $>90$ for males, $>80$ for females) & $158(81.4)$ & $80(81.6)$ & $78(81.3)$ & \\
\hline Waist to hip ratio & & & & 0.021 \\
\hline Normal & $20(10.3)$ & $15(15.3)$ & $5(5.2)$ & \\
\hline Obese ( $>0.90$ for males, $>0.85$ for females) & $174(89.7)$ & $83(84.7)$ & $91(94.8)$ & \\
\hline BMI-Southeast Asian classification, $\mathrm{kg} / \mathrm{m}^{2}$ & & & & 0.353 \\
\hline Underweight $(<18.5)$ & $3(1.5)$ & $2(2.0)$ & $1(1.0)$ & \\
\hline Normal (18.5-22.9) & $46(23.7)$ & $27(27.6)$ & $19(19.8)$ & \\
\hline Overweight ( $\geq 23.0)$ & $44(22.7)$ & $24(24.5)$ & $20(20.8)$ & \\
\hline Obese $(\geq 25.0)$ & $101(52.1)$ & $45(45.9)$ & $56(58.3)$ & \\
\hline BMI-WHO classification, $\mathrm{kg} / \mathrm{m}^{2}$ & & & & 0.345 \\
\hline Underweight $(<18.5)$ & $3(1.5)$ & $2(2.0)$ & $1(1.0)$ & \\
\hline Normal (18.5-24.9) & $90(46.4)$ & $51(52.0)$ & $39(40.6)$ & \\
\hline Overweight ( $\geq 25.0)$ & $72(37.1)$ & 31 (31.6) & $41(42.7)$ & \\
\hline Obese $(\geq 30.0)$ & $29(14.9)$ & $14(14.3)$ & 15 (15.6) & \\
\hline Blood pressure, $\mathrm{mmHg}$ & & & & 0.575 \\
\hline Normal & $85(43.8)$ & $41(41.8)$ & $44(45.8)$ & \\
\hline$>140 / 90$ & $109(56.2)$ & $57(58.2)$ & $52(54.2)$ & \\
\hline
\end{tabular}

BMI, body mass index; WHO, World Health Organization.

in the development of cognitive dysfunction. ${ }^{26}$ However, the direct cerebral effects of diabetes, leading to neuropathology and cognitive abnormalities, have not been clearly elucidated. In general, depression is known to complicate the impact of mild neurocognitive decline in patients. ${ }^{12}$ Cognitive impairment could therefore be a result of either depression or diabetes, and the coexistence of both conditions might possibly accelerate neurocognitive decline.

Various hypotheses have been proposed about the pathophysiology of cognitive dysfunction. Proposed pathogenic mechanisms of cognitive dysfunction in diabetes include chronic hypoglycemia, vascular disease, the cumulative effect of hypoglycemic events, and possible direct effects of insulin on the brain. ${ }^{27}$ Hypoglycemic effects may result in increased inflammation; oxidative stress; advanced glycation end products; and decreased neuronal repair and neurogenesis that may lead to direct neuronal injury, may manifest as brain atrophy, and may provide a structural basis for cognitive impairment. ${ }^{13}$ However, whether these factors individually or in combination mediate the pathogenesis of cognitive dysfunction is unclear.

Cognitive domains that have been studied in type 2 diabetes include memory, psychomotor speed, visuospatial functions, frontal executive functions, processing speed, verbal fluency, attention, and complex motor functions. ${ }^{28}$ In a review of literature on the association between impaired glucose tolerance, type 2 diabetes, and cognitive function, the authors concluded that the most consistently reported measures were impairment in verbal memory and processing speed, with preservation of functions in other areas including visuospatial function, attention, semantic memory, and language. ${ }^{29}$

Our finding that $64.3 \%$ of study subjects with cognitive impairment were $\geq 65$ years is similar to the study by Salthouse showing that age-related cognitive impairment is most commonly reported after 60 years of age. ${ }^{30}$ Langa and Levine ${ }^{31}$ and Harada et $\mathrm{al}^{32}$ reported that healthy individuals $>65$ years have mild cognitive impairment. Nooyens et al reported that middle-aged individuals with type 2 diabetes mellitus showed a greater decline in cognitive function than middle-aged individuals without diabetes. ${ }^{33}$

More than $60 \%$ of females had cognitive impairment in the present study. This finding is also supported by the Salthouse study. ${ }^{30}$ Similarly, Ferris et $\mathrm{al}^{34}$ showed cognitive decline to be more prevalent among females. In our population, education was significantly associated with cognitive impairment. Evidence for this association conflicts. Prakash et $\mathrm{al}^{35}$ and Brayne and Calloway ${ }^{36}$ showed that higher educational attainment is associated 
with reduced chance of cognitive impairment. On the other hand, studies by Andel et $\mathrm{al}^{37}$ and Stern et $\mathrm{al}^{38}$ showed that education attainment was associated with accelerated cognitive decline in patients with Alzheimer disease.

Disease characteristics were not significantly associated with cognitive dysfunction, similar to a study by Manschot et al. ${ }^{39}$ Ruis et al reported that modest cognitive decrements were identifiable at the early stage of type 2 diabetes. ${ }^{25}$ They also postulated that diabetes duration seemed to be linked to the effect sizes of the studies: the longer the duration of diabetes, the higher the noted effect size. Reitz et al proposed that hypertension may cause cognitive impairment through cerebrovascular disease, ${ }^{40}$ but our study did not identify any association between blood pressure levels and cognitive impairment, correlating the findings of Kuo et al. ${ }^{41}$ However, van Swieten et al reported impaired cognition in the hypertensive group. ${ }^{42}$

Among the anthropometric measurements assessed in the current study, only waist-to-hip ratio was significantly associated with cognitive impairment. However, a study by Kerwin et al among postmenopausal women showed that increased BMI was associated with poorer cognitive function in women with smaller waist-to-hip ratio, and increased waist-to-hip ratio was associated with higher cognitive abilities. ${ }^{43}$ The authors recommended further research to clarify the mechanism for this association.

In our study, the factors associated with cognitive dysfunction were older age group, female sex, lower educational qualification, low socioeconomic status, occupation, and high waist-to-hip ratio, a finding supported by Wright et al who reported that greater adiposity is an independent risk factor for cognitive decrements among African Americans. ${ }^{44}$

A strength of this study is the uniformity in data collection by investigators trained in community-based data collection and conduct of the interviews. A limitation is that a language barrier was perceived during some interviews, but this shortcoming was largely circumvented through the help of the auxiliary nurse midwives, especially for rapport building. Because of the cross-sectional nature of the study, only referrals could be provided to the subjects identified with mild cognitive impairment. Subjects with poor glycemic control or high blood pressure were also referred to the health centers. Follow-up could not be done, but the patients residing within the field practice area have easy and affordable access to healthcare facilities, and the best possible recommendations were provided. The small sample size, single-center assessment, unequal distribution of participants across social classes, and a predominance of subjects with a nonsevere disease condition (indicated by the low frequency of insulin usage) are other limitations of the study.

Early identification and regular follow-up of patients with mild cognitive impairment could initiate early psychosocial interventions and minimization of triggers to prevent further cognitive decline. As obesity was identified as a risk factor, promotion of regular physical activity could be recommended for patients with diabetes, not only to achieve better glycemic control but also to slow the process of cognitive impairment.
Assessing the baseline prevalence is the first step in designing programs to address any health issue. Health education pertaining to cognitive decline, early identification, and management can be effective only if patients and their caregivers are aware of the importance of cognition and its decline and are accepting of treatment.

\section{CONCLUSION}

More than half of the individuals with type 2 diabetes mellitus interviewed for this study had mild cognitive impairment. Potential predictors for cognitive impairment identified in the study were older age group, female sex, lower educational qualification, occupation, low socioeconomic status, and truncal obesity. Hence, screening and care need to be provided for older individuals with low literacy status who belong to the lower socioeconomic strata, as they were identified to be at high risk of cognitive impairment.

\section{ACKNOWLEDGMENTS}

The authors have no financial or proprietary interest in the subject matter of this article.

\section{REFERENCES}

1. Nathan DM. Long-term complications of diabetes mellitus. NEngl J Med. 1993 Jun 10;328(23):1676-1685.

2. Engelgau MM, Geiss LS, Saaddine JB, et al. The evolving diabetes burden in the United States. Ann Intern Med. 2004 Jun 1;140(11):945-950.

3. Zimmet $P$, Alberti KG, Shaw J. Global and societal implications of the diabetes epidemic. Nature. $2001 \mathrm{Dec}$ 13;414(6865):782-787.

4. Kapoor D, Bhardwaj AK, Kumar D, Raina SK. Prevalence of diabetes mellitus and its risk factors among permanently settled tribal individuals in tribal and urban areas in northern state of sub-Himalayan region of India. Int J Chronic Dis. 2014;2014:380597. doi: 10.1155/2014/380597.

5. Banoo H, Nusrat N, Nasir N. Type2 diabetes mellitus: a review of current trends. RAMA Univ J Med Sci. 2015;1(2):50-57. http://docplayer.net/39244694-Type2-diabetes-mellitus-areview-of-current-trends-key-words-diabetes-mellituspathophysiology-pathogenesis-etiology.html. Accessed August 7, 2019.

6. Luchsinger JA, Palmas W, Teresi JA, et al. Improved diabetes control in the elderly delays global cognitive decline. J Nutr Health Aging. 2011 Jun;15(6):445-449.

7. KodI CT, Seaquist ER. Cognitive dysfunction and diabetes mellitus. Endocr Rev. 2008 Jun;29(4):494-511. doi: 10.1210/er.2007-0034.

8. Cameron NE, Eaton SE, Cotter MA, Tesfaye S. Vascular factors and metabolic interactions in the pathogenesis of diabetic neuropathy. Diabetologia. 2001 Nov;44(11):1973-1988.

9. Cognitive Impairment: A Call for Action Now! Centers for Disease Control and Prevention. www.cdc.gov/aging/pdf/ cognitive_impairment/cogimp_poilicy_final.pdf. Accessed January 21, 2016.

10. Alosco ML, Spitznagel MB, van Dulmen M, et al. Cognitive function and treatment adherence in older adults with heart failure. Psychosom Med. 2012 Nov-Dec;74(9):965-973. doi: 10.1097/PSY.0b013e318272ef2a.

11. Martin LR, Williams SL, Haskard KB, Dimatteo MR. The challenge of patient adherence. Ther Clin Risk Manag. 2005 Sep;1(3):189-199. 
12. Munshi $M$, Grande $L$, Hayes $M$, et al. Cognitive dysfunction is associated with poor diabetes control in older adults. Diabetes Care. 2006 Aug;29(8):1794-1799.

13. Ravona-Springer $R$, Schnaider-Beeri $M$. The association of diabetes and dementia and possible implications for nondiabetic populations. Expert Rev Neurother. 2011 Nov;11(11):1609-1617. doi: 10.1586/ern.11.152.

14. de Galan BE, Zoungas S, Chalmers J, et al.; ADVANCE Collaborative group. Cognitive function and risks of cardiovascular disease and hypoglycaemia in patients with type 2 diabetes: the Action in Diabetes and Vascular Disease: Preterax and Diamicron Modified Release Controlled Evaluation (ADVANCE) trial. Diabetologia. 2009 Nov;52(11):2328-2336. doi: 10.1007/s00125-009-1484-7.

15. Tiwari SC, Tripathi RK, Farooqi SA, Kumar R, Srivastava G, Kumar A. Diabetes mellitus: a risk factor for cognitive impairment amongst urban older adults. Ind Psychiatry J. 2012 Jan;21(1):44-48. doi: 10.4103/0972-6748.110950.

16. Nasreddine ZS, Phillips NA, Bédirian V, et al. The Montreal Cognitive Assessment, MoCA: a brief screening tool for mild cognitive impairment. J Am Geriatr Soc. 2005 Apr;53(4): 695-699.

17. Thaneerat T, Tangwongchai S, Worakul P. Prevalence of depression, hemoglobin $\mathrm{A} 1 \mathrm{C}$ level, and associated factors in outpatients with type-2 diabetes. Asian Biomed. 2009;3(4):383-390.

18. Cernea S, Zoltai C, Berbecilă D, Şular FL. Prevalence of depression, anxiety and cognitive impairment in patients with type 2 diabetes from the central part of Romania. Acta Medica Marisiensis. 2016 May 20;62(2):209-216. doi: 10.1515/amma-2016-0014.

19. Alagiakrishnan K, Zhao N, Mereu L, Senior P, Senthilselvan A. Montreal cognitive assessment is superior to standardized mini-mental status exam in detecting mild cognitive impairment in the middle-aged and elderly patients with type 2 diabetes mellitus. Biomed Res Int. 2013;2013:186106. doi: 10.1155/2013/186106.

20. Pareekh U. Manual of socioeconomic status (rural). Mansayan 32, Netaji Subhash Marg, Delhi, India; 1981.

21. Chobanian AV, Bakris GL, Black HR, et al; National Heart, Lung, and Blood Institute Joint National Committee on Prevention, Detection, Evaluation, and Treatment of High Blood Pressure; National High Blood Pressure Education Program Coordinating Committee. The seventh report of the Joint National Committee on prevention, detection, evaluation, and treatment of high blood pressure: the JNC 7 report. JAMA. 2003 May 21;289(19):2560-2572.

22. Section 3: Data Collection Process. In: WHO STEPS Surveillance. World Health Organization. www.who.int/chp/steps/Part3_Section3.pdf. Updated January 26, 2017. Accessed January 15, 2016.

23. WHO Expert Consultation. Appropriate body-mass index for Asian populations and its implications for policy and intervention strategies. Lancet. 2004 Jan 10;363(9403):157-163. Erratum in Lancet. 2004 Mar 13;363(9412):902.

24. Waist Circumference and Waist-Hip Ratio: Report of a WHO Expert Consultation. World Health Organization. whqlibdoc.who.int/publications/2011/9789241501491_ eng.pdf. December 2008. Accessed January 15, 2016.

25. Ruis C, Biessels GJ, Gorter KJ, van den Donk M, Kappelle LJ, Rutten GE. Cognition in the early stage of type 2 diabetes. Diabetes Care. 2009 Jul;32(7):1261-1265. doi: $10.2337 / \mathrm{dc} 08-2143$.
26. Cox DJ, Kovatchev BP, Gonder-Frederick LA, et al. Relationships between hyperglycemia and cognitive performance among adults with type 1 and type 2 diabetes. Diabetes Care. 2005 Jan;28(1):71-77.

27. Bruce DG, Casey GP, Grange V, et al; Fremantle Cognition in Diabetes Study. Cognitive impairment, physical disability and depressive symptoms in older diabetic patients: the Fremantle Cognition in Diabetes Study. Diabetes Res Clin Pract. 2003 Jul;61(1):59-67.

28. Biessels GJ, van der Heide LP, Kamal A, Bleys RL, Gispen WH. Ageing and diabetes: implications for brain function. Eur J Pharmacol. 2002 Apr 19;441(1-2):1-14.

29. Kumar R, Looi JC, Raphael B. Type 2 diabetes mellitus, cognition and brain in aging: a brief review. Indian J Psychiatry. 2009 Jan;51 Suppl 1:S35-S38.

30. Salthouse TA. When does age-related cognitive decline begin? Neurobiol Aging. 2009 Apr;30(4):507-514. doi: 10.1016/j.neurobiolaging.2008.09.023.

31. Langa KM, Levine DA. The diagnosis and management of mild cognitive impairment: a clinical review. JAMA. 2014 Dec 17;312(23):2551-2561. doi: 10.1001/jama.2014.13806.

32. Harada CN, Natelson Love MC, Triebel KL. Normal cognitive aging. Clin Geriatr Med. 2013 Nov;29(4):737-752. doi: 10.1016/j.cger.2013.07.002.

33. Nooyens AC, Baan CA, Spijkerman AM, Verschuren WM. Type 2 diabetes and cognitive decline in middle-aged men and women: the Doetinchem Cohort Study. Diabetes Care. 2010 Sep;33(9):1964-1969. doi: 10.2337/dc09-2038.

34. Ferris S, Nordberg A, Soininen H, Darreh-Shori T, Lane R. Progression from mild cognitive impairment to Alzheimer's disease: effects of sex, butyrylcholinesterase genotype, and rivastigmine treatment. Pharmacogenet Genomics. 2009 Aug;19(8):635-646. doi: 10.1097/FPC.0b013e32832f8c17.

35. Prakash J, Ryali V, Srivastava K, Bhat PS, Shashikumar R. Cognitive reserve: the warehouse within. Ind Psychiatry J. 2011 Jul;20(2):79-82. doi: 10.4103/0972-6748.102475.

36. Brayne C, Calloway P. The association of education and socioeconomic status with the Mini Mental State Examination and the clinical diagnosis of dementia in elderly people. Age Ageing. 1990 Mar;19(2):91-96.

37. Andel R, Vigen C, Mack WJ, Clark LJ, Gatz M. The effect of education and occupational complexity on rate of cognitive decline in Alzheimer's patients. J Int Neuropsychol Soc. 2006 Jan;12(1):147-152.

38. Stern Y, Albert S, Tang MX, Tsai WY. Rate of memory decline in $A D$ is related to education and occupation: cognitive reserve? Neurology. 1999 Dec 10;53(9):1942-1947.

39. Manschot SM, Biessels GJ, Rutten GE, Kessels RP, Gispen WH, Kappelle LJ; Utrecht Diabetic Encephalopathy Study Group. Peripheral and central neurologic complications in type 2 diabetes mellitus: no association in individual patients. J Neurol Sci. 2008 Jan 15;264(1-2):157-162.

40. Reitz C, Tang MX, Manly J, Mayeux R, Luchsinger JA. Hypertension and the risk of mild cognitive impairment. Arch Neurol. 2007 Dec;64(12):1734-1740. doi: 10.1001/archneur.64.12.1734.

41. Kuo HK, Sorond F, Iloputaife I, Gagnon M, Milberg W, Lipsitz MA. Effect of blood pressure on cognitive functions in elderly persons. J Gerontol A Biol Sci Med Sci. 2004 Nov;59(11):1191-1194.

42. van Swieten JC, Geyskes GG, Derix MM, et al. Hypertension in the elderly is associated with white matter lesions and cognitive decline. Ann Neurol. 1991 Dec;30(6):825-830. 
43. Kerwin DR, Zhang Y, Kotchen JM, et al. The cross-sectional relationship between body mass index, waist-hip ratio and cognitive performance in postmenopausal women enrolled in the Women's Health Initiative (WHI). J Am Geriatr Soc. 2010 Aug;58(8):1427-1432. doi: 10.1111/j.1532-5415.2010.02969.x.
44. Wright RS, Cole AP, Ali MK, Skinner J, Whitfield KE, Mwendwa DT. Examining the influence of measures of adiposity on cognitive function in middle age and older African Americans. Arch Clin Neuropsychol. 2016 Feb;31(1):23-28. doi: 10.1093/arclin/acv086.

This article meets the Accreditation Council for Graduate Medical Education and the American Board of Medical Specialties Maintenance of Certification competencies for Patient Care and Medical Knowledge. 